\title{
Upaya Diplomasi Indonesia dalam Forum G20 untuk Mewujudkan Framework for Strong, Sustainable and Balanced Growth 2008-2012
}

\author{
Arum Tri Utami ${ }^{1}$, Renny Miryanti ${ }^{2}$, Tundjung Linggarwati ${ }^{3}$
}

\begin{abstract}
The aim of this article is to give an information about the effort of Indonesia's diplomacy in G20 to make Framework for Strong Sustainable and Balanced Growth. Indonesia's diplomacy in G20 is to reach the national interest. This national interest is make by the foreign policy. Diplomacy is the way to reach the national interest. Indonesia has take a lot of effort in G20 particullary to creat Framework for Strong, Sustainable and Balanced Growth. G20 is significant multilateral forum in the world. Therefore, Indonesia should maximise Indonesia's dipomacy to reach the national interest.
\end{abstract}

Keywords: Indonesia's diplomacy, G20, Framework for Strong Sustainable and Balanced Growth

\begin{abstract}
Abstrak
Penelitian ini berusaha menganalisis terkait dengan kepentingan, politik luar negeri dan upaya diplomasi Indonesia dalam forum G20. Tujuan dari penelitian ini untuk menganalisis bagaimana upaya diplomasi Indonesia dan apa saja kebijakan forum G20 yang dihasilkan dari upaya diplomasi Indonesia yang berkaitan dengan kepentingan nasional Indonesia khsusnya pada Framework for Strong, Sustainable and Balanced Growth . Fokus Penelitian ini ada pada periode 2008-2012. Tahun 2008 diambil karena pada tahun tersebut forum G20 pertama kalinya dirubah menjadi pertemuan tingkat tinggi kepala negara/ pemerintahan. Tahun 2012 dipilih karena pada tahun tersebut terjadi krisis Eurozone dan hal ini berakibat pada peningkatan peran G20 dalam dunia internasional
\end{abstract}

Keywords: diplomasi Indonesia, G20, Framework for Strong Sustainable and Balanced Growth

\section{Pendahuluan}

Forum G20 merupakan forum multilateral yang lahir dilatarbelakangi karena adanya krisis global (Hermawan, 2010). Krisis keuangan yang terjadi di Asia pada tahun 1997 merupakan salah satu krisis global yang meluas ke negara-negara lain di dunia
(Hermawan, 2010, hal. 32). Krisis finansial yang terjadi di beberapa negara membuat menteri keuangan negara maju berpikir bahwa sudah saatnya untuk mengajak negaranegara yang perekonomiannya menguat (emerging economies) untuk bergabung dalam diskusi tentang penataan struktur

\footnotetext{
${ }^{1}$ Alumnus Jurusan HI, FISIP Universitas Jenderal Soedirman, e-mail: arumtriutami@gmail.com

${ }^{2}$ Dosen Jurusan HI, FISIP Universitas Jenderal Soedirman, e-mail:renny.miryanti@gmail.com

${ }^{3}$ Dosen Jurusan HI, FISIP Universitas Jenderal Soedirman, e-mail:tunjung.el@gmail.com
} 
finansial global (kemenkeu.go.id, 2014).

Pada bulan September 1999, para menteri keuangan dan gubernur Bank Sentral dari G7 mengumumkan keinginan untuk memperluas dialog mengenai isu-isu ekonomi dengan membuat The Group of Twenty Finance Ministers and Central Bank Governors (G20) (G20 members, 2014). Anggota dari forum G20 terdiri dari 19 negara yaitu, Argentina, Australia, Brazil, Kanada, Republik Rakyat Tiongkok (RRT), Prancis, Jerman, India, Indonesia, Italia, Jepang, Korea Selatan, Meksiko, Rusia, Saudi Arabia, Afrika Selatan, Turki, Inggris, Amerika Serikat, dan Uni Eropa (Keuangan, 2010). Anggota G20 yang bukan negara seperti Ketua dari International Monetary and Financial Committe (IMFC) dan Ketua Development Committe (DC) secara ex-officio selalu diundang dalam pertemuan para menteri keuangan dan bank sentral G20 (Keuangan, 2010).

Indonesia menjadi anggota dari forum G20 sejak forum ini terbentuk pada tahun 1999 di Jerman. Tujuan Indonesia bergabung dalam forum $\mathrm{G} 20$ adalah memberikan peluang bagi Indonesia untuk turut menentukan agenda ekonomi internasional, terutama dalam penanganan krisis global dan melakukan perubahan arsitektur ekonomi dunia (Keuangan, 2010, hal. 48). G20 dianggap sebagai salah satu alat diplomasi ekonomi Indonesia untuk mendukung realisasi kepentingan nasionalnya yang tercermin dalam Rencana Pembangunan Jangka Menengah Nasional (RPJMN) 20102014 yang melihatkan bahwa 7 dari 11 prioritas nasional terkait dengan kepentingan ekonomi. ${ }^{4}$

Indonesia menjadi satu-satunya negara di kawasan Asia Tenggara yang menjadi anggota G20. Pemilihan Indonesia menjadi anggota G20 dikarenakan faktor ekonomi dan geografis. Dilihat dari faktor ekonomi berdasarkan data yang dirilis IMF dan World Bank pada tahun 2008, Indonesia menempati 20 besar kekuatan ekonomi dunia (Permana, 2012). Indonesia memperjuangkan kepentingan nasionalnya dan kepentingan negara berkembang agar negara berkembang dapat memiliki keterwakilan dan usulan yang lebih didengar dalam Multilateral Development Banks (MDBs) serta mendapat akses finansial yang lebih luas.

Pemimpin negara anggota G20 mengharapkan bahwa krisis global yang terjadi pada tahun 2008 tidak terjadi lagi, oleh karenanya dibuat Framework for Strong, Sustainable and Balanced Growth. Framework yang dijadikan tujuan

\footnotetext{
${ }^{4}$ Sebelas prioritas yang ada dalam RPJMN adalah Reformasi Birokrasi dan Tata Kelola; Pendidikan; Kesehatan; Penanggulangan Kemiskinan; Ketahanan Pangan; Infrastruktur; Iklim Investasi dan Usaha; Energi; Lingkungan Hidup dan Pengelolaan Bencana; Daerah Tertinggal, Terdepan, Tertular, dan Pasca-Konflik; Kebudayaan, Kreativitas dan Inovasi Teknologi
} 
pembentukan kebijakan dan komitmen bersama untuk bergerak bersama agar menciptakan strong, sustainable and balanced global growth. Kerangka kerja ini juga diharapkan dapat mengurangi pembangunan yang tidak merata di negara anggota G20. Komitmen dari negara-negara anggota G20 dibutuhkan untuk mewujudkan tujuan bersama ini.Indonesia telah melakukan inisiatifnya dalam proses G20 dan menjadi co -chair kelompok-kelompok kerja untuk menyusun detil agenda dan rencana aksi untuk merealisasikan inisiatif tersebut untuk mewujudkan FSSBG tersebut.

\section{Landasan Konsep}

\section{Politik Luar Negeri}

Politik luar negeri adalah kebijaksanaan suatu negara yang ditujukan ke negara lain untuk mencapai suatu kepentingan tertentu. Secara umum, politik luar negeri adalah suatu perangkat formula nilai, sikap, arah serta sasaran untuk mempertahankan, mengamankan dan memajukan kepentingan nasional di dalam percaturan internasional (Perwita , 2011). Henry Kissinger, menyatakan bahwa foreign policy begins when domestic politics ends. Hal ini melihatkan bahwa politik luar negeri dipengaruhi oleh lingkungan eksternal dan domestik (Linklater \& Burchill, 2010). Politik luar negeri dibuat suatu negara untuk mencapai kepentingan nasionalnya bisa melalui cara diplomasi. Proses perumusan politik luar negeri terdiri dari (Daniel, 2002):
- Menentukan tujuan (goal setting)

Dalam proses ini yang dilakukan adalah mengidentifikasi kepentingan nasional dan tujuan politik luar negeri yang akan dijadikan prioritas.

- Mengumpulkan, menafisirkan, dan melaporkan informasi (intelligence gathering, interpreting, and reporting) Setelah tujuan ditentukan, langkah penting selanjutnya adalah mengumpulkan sebanyak mungkin informasi yang berkaitan mengenai suatu isu yang sedang difokuskan, informasi ini juga mengenai faktorfaktor apa saja yang mempengaruhi.

- Perumusan pilihan (option formulation) Pilihan kebijakan yang berbeda dibuat untuk dapat menangani isu yang sedang diangkat sesuai dengan informasi yang didapat.

- Perencanaan dan pemograman (planning and programming)

Pada tahap ini akan ditentukan seberapa banyak info yang didapat, lama waktu kebijakan luar negeri akan sukses, jumlah waktu sebelum masalah terselesaikan, dampak politik yang diakibatkan.

- Pembuatan kebijakan (decision making Kebanyakan pengambil kebijakan memilih kebijakan yang mengakibatkan perubahan yang tidak signifikan. Kebijakan dipilih bukan 
yang terbaik tetapi yang memuaskan

- Artikulasi kebijakan (policy articulation)

Dalam tahap ini kebijakan akan dibuat seefektif mungkin dan dibutuhkan dukungan dari publik.

- Implementasi kebijakan (policy implementation)

Tahap ini merupakan aksi dari negara untuk merubah dari sebuah kebijakan menjadi praktek nyata.

- Pengawasan kebijakan (policy monitoring)

Negara harus mengawasi perkembangan dari kebijakan yang diambil dan harus menentukan efek yang diakibatkan dari kebijakan tersebut.

- Penilaian kebijakan (policy appraisal) Tahap ini merupakan proses memperkirakan akibat apa yang ditimbulkan dari kebiajakan tersebut.

- Modifikasi kebijakan (policy modification)

Jika penilaian kebijakan telah selesai dilakukan maka negara dapat memodifikasi kebijakan yang telah diambil.

- Penyimpanan memori (memory storage and recall)

Tahap akhirnya adalah penyimpanan memori atas kebijakan yang pernah dibuat. Tahap ini berfungsi agar negara dikemudian hari apabila menemui isu serupa dapat menggunakan atau memosifikasi kebiajakan yang pernah diambil.

Kepentingan nasional merupakan salah satu dari ciri pendekatan realisme, dengan tokoh seperti Hans J.Morgenthau, adanya kesamaan kepentingan antara negara yang satu dengan negara lainnya, ini yang menyebabkan aliansi pemerintahan perlu dibentuk (Karen , 1992). Aktor internasional dalam pendekatan realis dianggap sebagai aktor yang rasional dan selalu memilih pilihan yang rasional (rational choice). Setiap aktor selalu memikirkan cost and benefit dari setiap keputusan yang akan diambil. Morgenthau dalam politics among nation menyatakan bahwa setiap negara harus mengamankan kepentingannya terlebih dahulu, karena negara lain tidak akan membantu kecuali itu adalah kepentingannya.

Pemerintahan adalah alat bagi suatu negara untuk dapat berkomunikasi dengan dunia internasional. Tugas pemerintah adalah untuk menjadikan kemakmuran bagi rakyatnya, hal ini harus dilakukan dengan bekerjasama dengan pihak swasta dan dunia internasional. Oleh karena itu setiap negara di dunia pasti menyusun kepentingan nasionalnya dengan tujuan akhir kemakmurkan rakyatnya (Hans, 2010)

\section{Diplomasi Multilateral}

Isu-isu yang menjadi agenda dalam diplomasi multilateral sudah merupakan isu global yang menjadi kepentingan bersama dan harus diselesaikan secara bersama pula. 
Diplomasi multilateral memiliki beberapa keunggulan yang tidak dimiliki oleh diplomasi bilateral. Negara-negara dengan tingkat politik dan ekonomi yang berbeda dapat berinteraksi pada level yang sama (Hans, 2010, p. 80).

Berbeda dengan diplomasi bilateral yang lebih menekankan pada terciptanya kerjasama atau perjanjian antar dua negara yang hasilnya langsung dapat diimplementasikan, diplomasi multilateral cenderung bermain pada tataran penciptaan aturan dan norma, dimana negara-negara perlu mematuhi aturan tersebut dibawah supervisi institusi internasional. Multilateralisme merupakan sistem pengambilan keputusan dan bentuk kerjasama internasional yang paling demokratis yang ada saat ini, dan lembaga multilateral merupakan forum yang efektif dimana negara-negara berkembang memiliki hak suara sebagaimana halnya negara-negara maju (McGinnis , 2000).

\section{Framework for Strong, Sustainable and}

\section{Balanced Growth (FSSBG)}

Pada pertemuan tingkat tinggi G20 di Pittsburgh tanggal 24-25 September 2009 disepakati adanya tujuan dan cita-cita bersama yang tertuang dalam Framework for Strong, Sustainable and Balanced Growth. FSSBG ini berisikan komitmen bersama dari negara anggota G20 untuk bekerja bersama, menilai bagaimana kebijakan yang diambil, dan untuk mengevaluasi apakah kebijakan itu sudah sesuai atau belum.

Reformasi dilakukan untuk mencegah timbulnya kembali asset bubbles $^{5}$ dan munculnya ketidakseimbangan finansial global melalui berbagai kebijakan untuk mencegahnya. FSSBG dilandasi pada tujuan untuk meningkatkan kemakmuran, integritas, dan tranparansi yang tertuang dalam langkahlangkah (g20.org, 2014):

- Penguatan Sistem Peraturan Finansial Internasional

$\diamond \quad$ Pengawasan yang lebih ketat dengan penguatan institusional Financial Stability Board (FSB) dengan melalui kerangka kerja tersebut.

$\diamond$ Menyeimbangkan antara kebijakan mikro dan makro

$\diamond$ Memanggil menteri keuangan dan gubernur Bank Sentral untuk mencapai sebuah perjanjian dalam :

- Membangun kualitas modal yang tinggi dan mengurangi procyclicality ${ }^{6}$. Akan membuat perjanjian untuk meningkatkan kualitas dan kuantitas bank modal pada tahun 2010 dengan mengadopsi Basel II Capital Framework $^{7}$

- Reformasi praktek kompensasi untuk mendukung stabilitas finansial.

- Peningkatan perdagangan off exchange yang dilakukan antara 2 pihak tanpa terdapat pengawasan atas transasksi ini dalam pasar derivatif. Semua peraturan off

\footnotetext{
${ }^{5}$ Penggelembungan aset yang apabila bermasalah akan dikonversikan menjadi hutang pemerintah
} 
ecxhange8 pasar derivatif harus diterapkan pada landasan perdagangan yang kemudian harus disesuaikan pada akhir tahun 2012.

- Mengatasi resolusi lintas batas dan ketentuan institusi finansial pada akhir tahun 2010. Harus ada manajemen krisis dan kerangka kerja formal dalam penanganan krisis.

Adanya Financial Action Task Force untuk melawan pencucian uang.

- Modernisasi Institusi Global

Modernisasi dilakukan untuk stabilitas finansial global, mempercepat pembangunan berkelanjutan, dan mengurangi jumlah kemiskinan. Akan melihat perkembangan dari International Financial Institution (IFIs)

- Reformasi Misi, Mandat dan tata kelola Development Banks

G20 terus mendorong upaya yang dilakukan oleh Multilateral Development Banks (MDBs) serta berbagai inovasi yang mereka buat dengan menerima pinjaman dari kalangan pengusaha dan kelompok lainnya. G20 juga mendorong MDBs di negara berkembang agar negara berkembang dapat mendapatkan bantuan pinjaman dengan mudah dan cepat. Mendorong agar World Bank dan MDBs regional melakukan koordinasi yang tepat guna membantu masalah keuangan dan finansial global.

- Ketahanan Energi dan Perubahan Iklim Akses yang mudah dan energi yang bersih sangat penting untuk pertumbuhan berkelanjutan. Negara anggota G20 berkomitmen untuk menciptakan ketahanan energi melalui langkah-langkah :

$\diamond$ Meningkatkan stabilitas dan transparansi pasar energi dengan data produksi yang transparan, akurat dan tepat waktu. Menyesuaikan stok dengan permintaan. Peningkatan penelitian terhadap sumber energi alternatif lainnya yang kemudian dikelola oleh lembaga terkait.

$\diamond$ Meningkatkan pengawasan dan regulasi pasar dengan menerapkan aturan yang dikeluarkan oleh International Organization of Securities Commissions (IOSC)

$\diamond$ Peningkatan efisiensi energi maka akan membuat peran positif dukungan terhadap ketahanan energi dan perjuangan melawan perubahan iklim.

$\diamond$ Meminta institusi terkait seperti IMF, World Bank, OPEC, IEA, OECD untuk memberikan laporan mengenai analisis ruang lingkup dari subsidi energi dan saran untuk melaksanakan proses tersebut.

$\diamond$ Mempromosikan langkah konservasi

\footnotetext{
${ }^{6}$ Naik turunnya siklus ekonomi karena banyaknya variabel yang mengakibatkannya

7 Sebuah kerangka perbankan yang dibentuk dengan tujuan untuk meningkatkan ketahanan dan kesehatan sistem keuangan dengan menitikberatkan pada perhitungan permodalan yang berbasis resiko, proses review oleh pengawas dan disiplin pasar

${ }^{8}$ Penjualan surat berharga yang berada diluar pasar derivatif suatu negara
} 
untuk melindungi alam dengan cara menciptakan teknologi yang ramah lingkungan

$\diamond$ Menerapkan prinsip-prinsip dari United Nations Framework Convention on Climate Change (UNFCC)

- Penguatan dukungan kepada yang paling rentan

Negara G20 menaruh perhatian yang lebih kepada efek negatif yang ditimbulkan oleh krisis terhadap low income countries (LICs) dalam bidang kesehatan, pendidikan, dan infrastruktur. UN's new Global Impact Vulnerabillity Alert System akan membantu memantau. Bantuan dari MDBs dan IMF sangat diperlukan dalam penanganan krisis di LICs. Dibutuhkan langkah bilateral dan multilateral guna menjamin masalah kesehatan, pendidikan dan infrastrukturdi LICs. Mendorong negara berkembang untuk mengadakan pemerintahan yang bersih dari korupsi.

- Ekonomi Global yang terbuka

Melanjutkan kebangkitan kembali dalam perdagangan dunia dan investasi menjadi sangat penting untuk memulihkan pertumbuhan global. Berkomitmen untuk memerangi proteksionisme. Negara anggota G20 berkomitmen untuk mengurangi hambatan perdagangan. Akan meminimalisir efek negatif dari perdagangan global dan investasi terhadap lingkungan domestik melalui kebijakan dalam negeri termasuk kebijakan fiskal serta mendukung sektor keuangan. Tidak akan membatasi aliran modal di seluruh dunia, terutama ke negara-negara berkembang. Menyambut baik laporan dari WTO, OECD, IMF dan konferensi PBB, pada perdagangan global dan memantau situasi di masing-masing negara.

\section{Gambaran Umum}

Inisiatif pembentukan G20 di tahun 1999 tidak dapat dilepaskan dari peran G7. Pada pertemuan menteri-menteri keuangan G7 pada bulan Juni 1999 di Kohln, dinyatakan bahwa mereka akan mengadakan kerjasama untuk membentuk mekanisme informal antara negara-negara yang penting secara sistemik dalam kerangka sistem Bretton Woods. Pernyataan ini kemudian direalisasikan dengan diadakannya pertemuan Menteri-menteri Keuangan dan Gubernur Bank Sentral tanggal 25 September 1999, dimana diumumkan suatu usulan tentang perlunya perluasan dialog tentang isu-isu kebijakan ekonomi dan finansial dan kerjasama untuk menciptakan pertumbuhan ekonomi dunia yang stabil dan berkelanjutan yang menguntungkan bagi semua pihak. Negara anggota G7 kemudian mengundang Menteri Keuangan dan Gubernur Bank Sentral dari beberapa negara yang dipandang sistemik dalam pertemuan pada bulan Desember 1999 di Berlin (international.gc.ac).

Keanggotaan dalam G20 terdiri atas negara-negara yang secara ekonomi memiliki 
pengaruh cukup signifikan yang merepresentasikan seluruh wilayah di dunia beserta Uni Eropa dan Bretton Woods Institutions yang mampu mengisi ketimpangan dalam struktur tata kelola sistem ekonomi dan keuangan internasional. Keduapuluh negara anggota itu adalah Argentina, Australia, Brazil, Kanada, Republik Rakyat Tiongkok (RRT), Prancis, Jerman, India, Indonesia, Italia, Jepang, Korea Selatan, Meksiko, Rusia, Saudi Arabia, Afrika Selatan, Turki, Inggris, Amerika Serikat, dan Uni Eropa (G20, 2015).

Tujuan utama pembentukan G20 adalah menyediakan suatu forum diskusi permanen yang intensif bagi para pembuat kebijakan keuangan dalam rangka menciptakan stabilitas keuangan global melalui upaya pencegahan dan penyelesaian krisis keuangan internasional. Forum ini memiliki tanggung jawab kepada negara anggotanya, juga kepada perbaikan dan peningkatan kualitas pertumbuhan ekonomi global secara keseluruhan. Untuk mencapai tujuan tersebut, G20 telah menetapkan sasaran yang diwujudkan dalam komitmen untuk meletakkan sebuah kerangka pertumbuhan ekonomi yang kuat, berkesinambungan, dan berimbang dalam jangka panjang atau yang dikenal dengan Framework for Strong, Sustainable, and Balanced Growth (communique, 2015).

Pertemuan G20 dilaksanakan secara teratur dengan keketuaan yang di rotasi, diseleksi berdasakan keterwakilan regional setiap tahunnya. Setiap tahunnya, salah satu negara anggota diberikan tanggung jawab untuk mengatur pertemuan tingkat tinggi kepala negara/pemerintahan dan memastikan bahwa pertemuan sesuai dengan yang direncanakan. G20 tidak memiliki sekretariat yang permanen. Menteri Keuangan dan Kepala Bank Sentral mengadakan beberapa pertemuan setiap tahunnya untuk meletakkan dasar bagi pembuat kebijakan oleh Kepala negara/ pemerintahan (Kementerian Luar Negeri ; 2012).

\section{Kepentingan Indonesia}

Indonesia bergabung dalam forum G20 sejak forum ini terbentuk pada tahun 1999. Sejak bergabung dalam G20, Indonesia telah menunjukkan peran aktif dalam pembahasan isu-isu makroekonomi global, dan telah menyampaikan sejumlah komitmen penting terkait kebijakan fiskal, moneter, sektor keuangan dan pelaksanaan reformasi struktural. Indonesia dipandang konsisten dengan terus menyuarakan usulan-usulan yang mampu meningkatkan kapasitas negara berkembang, terutama dalam hal peningkatan kualitas kebijakan ekonomi (Djumala, 2010).

Alasan mengapa Indonesia bergabung dalam forum G20 berdasarkan pengalaman krisis yang terjadi pada tahun 1997, Indonesia merupakan salah satu negara yang rentan terhadap dampak dari krisis global. Oleh karenanya, Indonesia memandang bahwa 
forum G20 ini dapat dijadikan sebagai forum agar perekonomiannya stabil dan krisis tidak terjadi lagi. Apabila krisis terjadi, Indonesia berharap melalui forum ini dapat dibuat langkah-langkah penanganan krisis jangka pendek dan jangka panjang (thejakartaglobe, 2015).

G20 dianggap sebagai salah satu alat diplomasi ekonomi Indonesia untuk mendukung realisasi kepentingan nasionalnya yang tercermin dalam Rencana Pembangunan Jangka Menengah Nasional (RPJMN) 20102014. Kepentingan nasional Indonesia dalam forum G20 adalah agar perekonomiannya stabil terhadap resiko krisis global, yang kemudian dengan tujuan akhir kemakmuran bagi rakyat Indonesia. Kepentingan nasional selanjutnya adalah untuk meningkatkan peranan Indonesia dalam dunia internasional ${ }^{9}$.

Berdasarkan Undang-Undang Nomor 25 Tahun 2004 tentang Sistem Perencanaan Pembangunan Nasional, dan Peraturan Pemerintah Nomor 20 tahun 200 tentang Rencana Kerja Pemerintah mengamanatkan setiap Kementerian/Lembaga menyusun Rencana Strategi sebagai penjabaran dari Rencana Pembangunan Jangka Menengah Nasional (RPJMN). Pada arah kebijakan luar negeri Kementerian Luar Negeri Republik Indonesia salah satu bidangnya adalah meningkatkan kualitas diplomasi ekonomi dalam forum multilateral yang dilakukan melalui antara lain : partisipasi aktif Indonesia dalam forum multilateral seperti WTO, APEC, G20, G33 untuk memperjuangkan kepentingan Indonesia dan negara berkembang. Prakarsa dan gagasan Indonesia perlu diperjuangkan dalam setiap pertemuan (kemlu, 2015).

Pencapaian kepentingan nasional Indonesia dimulai dari perumusan kebijakan dalam negeri untuk kemudian kebijakan tersebut diperjuangkan di dalam pertemuan tingkat tinggi G20. Perumusan kebijakan dalam negeri terkait kebijakan yang akan dibawa oleh Indonesia dalam forum G20 yaitu melalui dua track yaitu finance track ${ }^{10}$ dan sherpa track ${ }^{11}$. Finance track dikoordinir oleh Kementerian Keuangan (badan kebijakan fiskal) dan Bank Indonesia, khusus untuk membahas isu-isu mengenai keuangan yaitu penanganan inflasi, perpajakan serta upaya untuk peningkatan pertumbuhan ekonomi (Lazuardy, 2015).

\section{Upaya Diplomasi Indonesia}

Politik luar negeri dan diplomasi Indonesia dilakukan untuk memastikan terjaminnya kepentingan nasional, tujuan pembangunan nasional, pertumbuhan ekonomi, kesejahteraan rakyat, konsolidasi dan pencapaian keadilan sosial bagi seluruh rakyat Indonesia. Pergeseran posisi Indonesia dari negara berkembang menjadi negara emerging serta dari negara penerima bantuan

\footnotetext{
${ }^{9}$ Republik Indonesia, Peraturan Presiden Republik Indonesia nomor 5 tahun 2010 tentang Rencana Pembangunan Jangka Menengah Nasional 2010-2014
} 
menjadi negara penerima sekaligus sebagai negara donor, membutuhkan penyesuaian profil Indonesia di dunia luar. Peran aktif Indonesia di G20 menjadi penting karena G20 dapat dijadikan sebagai wadah instrumen politik luar negeri Indonesia dalam mendukung upaya Indonesia menjadi negara maju pada tahun 2025. Tiga hal yang secara konsisten terus didorong oleh Indonesia (Permana, Tiga hal yang konsisten diperjuangkan Indonesia, 2015):

(i) Pembiayaan infrastruktur, yang harus menjadi agenda tetap para Menteri Keuangan, khususnya terkait pemenuhan ketersediaan pendanaan jangka panjang. Investasi infrastruktur juga dapat menjaga momentum pertumbuhan ekonomi dalam jangka menengah dan membantu mengurangi ketidakseimbangan global

(ii) Indonesia mendukung Global Partnership on Financial Inclusion sebagai platform untuk mewujudkan agenda financial inclusion dalam skala global

(iii) Pada isu ketahanan pangan, Indonesia terus berupaya mendorong peningkatan produksi dan produktivitas pertanian antara lain melalui peningkatan investasi dan penguatan penelitian dan pengembangan, serta melalui pengupayaan mekanisme pembiayaan produksi dan produktivitas pertanian antara lain melalui peningkatan investasi dan penguatan penelitian dan pengembangan, serta melalui pengupayaan mekanisme pembiayaan praktis dan inovatif, transfer pengetahuan, dan memberi fokus pada penelitian komoditas tertentu seperti padi.

Indonesia menempatkan prioritas pada agenda-agenda pembangunan. Hal ini tidak saja sesuai dengan kebutuhan Indonesia, tetapi juga penting dalam konteks mendorong pertumbuhan global yang lebih berkelanjutan. Agenda pembangunan utama yang diangkat oleh Indonesia termasuk pembiayaan infrastruktur, keuangan inklusif, dan ketahanan pangan. Pembiayaan infrastruktur sendiri masih dibutuhkan untuk mendorong pembangunan nasional dan sejalan dengan rencana-rencana pembangunan nasional seperti Rencana Pembangunan Jangka Menengah Nasional (RPJMN), Rencana Pembangunan Jangka Panjang Nasional (RPJPN), dan Master Plan Percepatan Pembangunan Ekonomi Indonesia (MP3I) (Keuangan, 2010, p. 78).

Banyak manfaat yang Indonesia peroleh dari keikutsertaannya dalam G20.

${ }^{10}$ Finance track atau jalur keuangan merupakan pertemuan G20 yang membahas dan mengatur mengenai isu-isu keuangan

${ }^{11}$ Sherpa track disebut sebagai jalur non keuangan yang merupakan pertemuan G20 yang membahas dan mengatur mengenai isu-isu non keuangan 
Indonesia menjadi co-chair dalam kelompok kerja untuk reformasi Bank Dunia dan MDBs. Indonesia dapat memperoleh akses keuangan yang lebih besar bagi pengembangan ekonomi Indonesia. Selain itu Indonesia juga mendapat suara dan keterwakilan negara berkembang yang lebih besar dalam MDBs (jakartapost, 2009).

Salah satu peran penting Indonesia dalam G20 adalah usulan mengenai General Expenditure Support Fund (GESF) pada KTT Washington DC, 15 November 2008. GESF merupakan kemudahan bagi negara berkembang untuk mendapatkan dana likuiditas dari IMF dan Bank Dunia. Tujuan utama dari GESF adalah untuk membantu pembangunan infrastruktur, menciptakan lapangan pekerjaan, dan mencapai target yang ditetapkan oleh MDGs 2015 (Jakartapost, 2014).

Persyaratan negara penerima GESF (Yudhoyono, 2009):

$\diamond$ Mengandalkan pasar untuk sejumlah besar anggaran

$\diamond$ Mengalami kesulitan dalam mendapat persetujuan eksternal

$\diamond$ Memiliki track record yang bagus dalam hal fiskal disiplin selama 3 tahun terakhir.

$\diamond$ Secara konsisten melakukan reformasi pemerintahan dan peningkatkan transparansi.

$\diamond$ Dapat membuat matriks kebijakan untuk langkah-langkah peningkatan $\diamond$ Memiliki pengalaman dalam pengurangan pertumbuhan ekonomi

$\diamond$ Memiliki banyak orang miskin (lebih dari $20 \%$ dari populasi).

Perubahan arsitektur keuangan internasional didorong melalui reformasi dan penguatan sumber daya IMF. Indonesia mendukung reformasi tata kelola IMF yang dapat mencerminkan bobot besaran perekonomian suatu negara dan kontribusi negara-negara berkembang pada IMF. Peran negara berkembang juga meningkat dengan tambahan sumber daya yang dijanjikan pada pertemuan Los Cabos. Dalam konteks ini, dukungan Indonesia juga turut berkontribusi pada peningkatan peran negara berkembang (Block, 2011).

Agenda mengenai reformasi MDBs pada awalnya hanya akan menitikberatkan pada negara-negara di kawasan Afrika. Menurut Indonesia agenda MDBs seharusnya lebih tersebar, salah satunya di Asia. Hal tersebut terus diperjuangkan oleh Indonesia. Hasil dari usulan Indonesia tersebut menjadikan adanya mekansime joint plan antara MDBs dengan Asian Infrastructure Fund (AIF). Indonesia menyerahkan proposal inisiatif infrastruktur yang akan dijadikan program di dalam negeri Indonesia, dan mendapatkan bantuan dana pembangunan dari AIF (Keuangan, 2010, p. 100).

Pada KTT G20 di Seoul, Korea Selatan tanggal 11-12 November 2010, ASEAN 
ditetapkan sebagai permanent obsersver, hal ini merupakan hasil lobi Indonesia yang disampaikan secara khusus oleh Presiden Susilo Bambang Yudhoyono kepada para pemimpin negara anggota G20 pada KTT Pittsburgh tahun 2009. Dalam KTT tersebut, Presiden Susilo Bambang Yudhoyono mendorong agar dimensi pembangunan menjadi bagian integral dari FSSBG. Usulan ini mendapat dukungan luas dan telah dimasukkan ke dalam deklarasi. Dalam konteks pembangunan, presiden juga mendorong pentingnya financial inclusion dengan memperluas akses finansial bagi penduduk berpendapatan rendah serta UKM. Hal ini selain bertujuan mengentaskan kemiskinan sekaligus dapat mendorong potensi pembangunan yang ada (kemlu, Indonesia Dorong Agenda Pembangunan Menjadi Bagian Integral Kerjasama G20, 2015).

Pada KTT Toronto, Kanada, 26-27 Juni 2010, Presiden Susilo Bambang Yudhoyono menyampaikan pandangannya bahwa G20 harus menjaga momentum perbaikan ekonomi global pasca krisis, khususnya terkait kecemasan pasar akibat situasi fiskal di beberapa negara maju. Sebagai salah satu negara anggota G20 yang paling berhasil menjaga keseimbangan fiskal dan menurunkan tingkat hutang, Indonesia menyarankan agar negara maju harus menyusun program konsolidasi fiskal yang kredibel karena tekanan fiskal di negara maju akan berdampak pada biaya pendanaan di negara berkembang dan menghambat agenda pembangunan (Kemenkeu, 2015).

Pada KTT di Cannes, Prancis, tanggal 3-4 November 2011, Presiden RI menyampaikan keyakinan bahwa negaranegara Eropa dapat menyelesaikan masalah di eurozone. Selain itu, Presiden RI juga menekankan isu ketahanan pangan, investasi sektor pertanian dan juga peningkatan penelitian dan pengembangan yang penting dalam meningkatkan produktifitas. Presiden menyampaikan pentingnya permintaan dan penawaran pangan menjadi perhatian global. Kerja sama internasional untuk mencapai ketahanan pangan dalam kerangka G20 juga harus didukung kerja sama yang melibatkan organisasi-organisasi regional seperti ASEAN. Indonesia juga menjadi co-facilitator dalam kelompok kerja pembangunan untuk pilar growth with resilience khususnya isu social protection (Keuangan, 2010, p. 119).

Sebagai co-chair G20 Anti-Coruption Working Group, Presiden RI juga menjelaskan kesepakatan yang telah dicapai dalam bentuk Anti Corruption Action Plan yang berisi antara lain memberlakukan ketentuan hukum terhadap tindak penyuapan internasional, mencegah pejabat yang korupsi mendapat akses terhadap sistem keuangan global. Memperkuat rezim anti pencucian uang, serta mendukung penguasaan kembali hasil-hasil korupsi yang dilarikan ke luar negeri. Secara umum, KTT G20 di Pittsburgh, Indonesia 
berhasil memasukkan tiga agenda nasional yang penting kedalam kesepakatan G20 yaitu terkait dengan agenda pembangunan, financial inclusion, dan anti korupsi (kemlu, Indonesia Dorong Agenda Pembangunan Menjadi Bagian Integral Kerjasama G20, 2015).

Pada KTT di Los Cabos, Indonesia telah mengusulkan agar G20 memberikan perhatian lebih serius kepada tantangan pembiayaan infrastruktur, tidak saja mendukung program pembangunan global sebagaimana tertuang dalam MDGs, namun juga untuk meningkatkan pertumbuhan ekonomi dan mengurangi ketidakseimbangan global. Usulan ini disepakati oleh para pemimpin G20 dan dimasukkan dalam deklarasi para pemimpin G20 untuk tindak lanjut ke depan (Keuangan, 2010, p. 105).

KTT G20 di Los Cabos, Meksiko 1819 Juni 2012 menghasilkan sebuah komunike bersama para pemimpin negara G20 mengenai Financial Inclusion Peer Learning Program. Program tersebut akan difokuskan untuk mendukung pegembangan strategi keuangan yang inklusif di seluruh dunia. Keuangan inklusif adalah ketersediaan fasilitas akses dan layanan jasa keuangan yang sesuai khususnya untuk masyarakat berpendapatan rendah dengan biaya yang terjangkau, relatif mudah dan cepat sehingga membantu transaksi ekonomi sehari-hari untuk memenuhi kebutuhan hidup maupun usaha masyarakat. G20 mengidentifikasi bahwa masih terdapat hampir 2,5 milyar orang dewasa di dunia yang belum memiliki akses terhadap layanan keuangan/perbankan (Keuangan, 2010, p. 257).

\section{Kesimpulan}

G20 merupakan sebuah forum multilateral yang dibentuk pada tahun 1999 . Forum G20 kemudian dirubah menjadi pertemuan tingkat tinggi kepala negara/ pemerintahan pada tahun 2008. Tujuan utama pembentukan G20 adalah menyediakan suatu forum diskusi permanen yang intensif bagi para pembuat kebijakan keuangan dalam rangka menciptakan stabilitas keuangan global melalui upaya pencegahan dan penyelesaian krisis keuangan internasional. G20 telah menetapkan sasaran yang diwujudkan dalam komitmen untuk meletakkan sebuah kerangka pertumbuhan ekonomi yang kuat, berkesinambungan, dan berimbang dalam jangka panjang atau yang dikenal dengan Framework for Strong, Sustainable, and Balanced Growth.

Signifikansi G20 : Jumlah anggotanya yang 20 dianggap signifikan dan sistemik. Keduapuluh anggota secara keseluruhan menguasai 80 persen lebih perekonomian dunia yang ditandai dengan pertumbuhan GDP, penguasaan aliran investasi asing, pasar, perdagangan dunia dan populasi dunia, melakukan berbagai komitmen dan kebijakan untuk penanganan krisis 2008, mengeluarkan langkah-langkah dalam penanganan krisis eurozone 2011.

G20 dijadikan sebagai alat diplomasi 
Indonesia untuk mewujudkan kepentingan nasionalnya yang tercermin dalam RPJMN 2010-2014. Tiga hal yang secara konsisten terus didorong oleh Indonesia adalah pembiayaan infrastruktur, Indonesia mendukung Global Partnership on Financial Inclusion sebagai platform untuk mewujudkan agenda financial inclusion dalam skala global dan peer learning program, pada isu ketahanan pangan, Indonesia terus berupaya mendorong peningkatan produksi dan produktivitasa pertanian.

Indonesia telah melihatkan kontribusinya dalam forum G20 dengan peran dan inisiatifnya. Hal ini harus terus didorong oleh Indonesia agar dapat mencapai kepentingan nasional Indonesia. Dengan memainkan peran yang aktif dalam G20 tentunya Indonesia mendapatkan banyak manfaat. Manfaat tersebut antara lain peningkatan peran Indonesia, dapat menentukan agenda internasional, mengangkat agenda nasional kedalam agenda internasional, dan lebih mudahnya Indonesia dalam memperoleh dana pembangunan internasional.

G20 menjadi salah satu alat diplomasi multilateral Indonesia di tingkat global. Indonesia harus mensinergikan usulan dalam G20 dengan keanggotaan Indonesia dalam forum multilateral lainnya. Hal ini untuk meningkatkan efektivitas diplomasi Indonesia dan memudahkan Indonesia dalam mencapai kepentingan nasionalnya. Selain itu, Indonesia juga harus memiliki pandangan yang kuat dalam forum-forum multilateral agar dapat mengedepankan kepentingan negara berkembang khususnya kepentingan nasionalnya. 


\section{Daftar Pustaka}

G20 members. (2014, September 3). Diambil kembali dari g20.org : http://www.g20.org/ g20_members

kemenkeu.go.id. (2014, September). Diambil kembali dari kemenkeu.go.id: www.kemenkeu.go.id\%2Fsites\%2Fdefault\%2Ffiles\%2FEkonomi\%2520Biru\% 2520Maritim\%2520Indonesia\%2520Berkelanjutan.pdf

Block, M. J. (2011). Leveraging Internationalism : Indonesian Perception on the G20. The Indonesian Quarterly, 39/no.4, 351.

communique, t. (2015, Februari 2). Leaders Declaration Pittsburgh Summit 2009. Dipetik Februari 2, 2015, dari http://www.g20.utoronto.ca/2009/2009communique0925.html\# growth: http://www.g20.utoronto.ca/2009/2009communique0925.html\#growth

Daniel, P. S. (2002). Contemporary International Relation (Framework for Understanding) (Vol. 6). NewYork: Longman.

Djumala, D. (2010, Juni ). G20 dan Diplomasi Indonesia. Jurnal Diplomasi (Membangun Ekonomi 
dengan Diplomasi Ekonomi, II/No.2, 63.

G20, M. o. (2015, Februari 2). g20.org. Dipetik Februari 2, 2015, dari Membership of G20: https:// g20.org/about-g20/g20-members/g20-world/

Hans, M. J. (2010). Politik Antar Bangsa. Jakarta: Yayasan Pustaka Obor Indonesia.

Hermawan, Y. (2010). Formalizing the G20 outreaching contact groups and civil G20. Dalam Thomas , \& P. Wolf, G20 and Global Development (hal. 30). Fues: Bonn.

History and Membership of the G20. (t.thn.). Dipetik Februari 2, 2015, dari international.gc.ca: http://www.international.gc.ca/g20/history-histoire.aspx?lang=eng

international.gc.ac. (t.thn.). international.gc.ca. Dipetik Februari 2, 2015, dari The History and Membership of G20: http://www.international.gc.ca/g20/history-histoire.aspx?lang=eng

jakartapost. (2009, April 3). Indonesia and the G20. Dipetik Februari 4, 2015, dari thejakartapost.com: http:/www.thejakartapost.com/news/2009/04/03/indonesia-andg20.html

jakartapost. (2014, November 18). Does the G20 matter for Indonesia. Dipetik Maret 2, 2015, dari thejakartapost.com: http://www.thejakartapost.com/news/2014/11/19/does-g20-matterindonesia.html

Karen , M. A. (1992). Essentials of International Relations (Vol. II). New York: W.W Norton\&Company Inc.

Kemenkeu. (2015, Maret 5). Pertemuan G20 Toronto Kanada 26-27 Juni 2010. Dipetik Maret 5, 2015, dari kemenkeu.go.id: Kementerian Keuangan Republik Indonesia Biro Komunikasi dan Layanan Informasi Keterangan Pers Pertemuan Pemimpin G20

Kementerian Luar Negeri ;. (2012). Indonesia and the G20. Buletin Direktorat Jendral Multilateral Kementerian Luar Negeri RI, I, 21.

kemlu. (2015, Maret 4). Arah Kebijakan Luar Negeri. Dipetik Maret 4, 2015, dari kemlu.go.id: http://www.kemlu.go.id/Pages/Polugri.aspx?IDP=21\&l=id

kemlu. (2015, Maret 2). Indonesia Dorong Agenda Pembangunan Menjadi Bagian Integral Kerjasama G20. Dipetik Maret 2, 2015, dari kemlu.go.id: http://www.kemlu.go.id/ layouts/mobile/PortalDetail-PressReleaseLike.aspx?l=id\&ItemId=410a384e-4e8b-4a439f56-460f2d8b2f01

Keuangan, P. K. (2010). G20, Ekonomi Global, dan Peranan Indonesia. Jakarta: Kementerian Keuangan.

Lazuardy, N. (2015, Januari 29). Indonesia dan G20. Staff Direktorat PELH Kemlu . (A. T. Utami, Pewawancara)

Linklater , A., \& Burchill, S. (2010). Theories of International Relations. (M.Sobbirin, Penerj.) Jakarta : Nusa Media .

McGinnis , J. O. (2000). The Political Economy of Global Multilateralism. Chicago Journal of International Law, 6.

Permana , W. (2012). Tata Kelola Global dan G20. Jakarta: Pusat Pengkajian dan Pengembangan Kebijakan pada Organisasi Internasional Badan Pengkajian dan Pengembangan Kebijakan Kementerian Luar Negeri .

Permana, W. (2015, Agustus 3). Tiga hal yang konsisten diperjuangkan Indonesia. Staf Direktorat Pusat Pengkajian dan Pengembangan Kebijakan pada Organisasi Internasional Kementerian Luar Negeri . (A. T. Utami, Pewawancara) Jakarta .

Perwita , B. A. (2011). Pengantar Ilmu Hubungan Internasional. Bandung, Indonesia : PT. 
Remaja Rosdakarya .

thejakartaglobe. (2015, Febaruari 8). G20 Including Indonesia, to take leading role in coordinating global economy : US Official. Dipetik Februari 8, 2015, dari thejakartaglobe.com: thejakartaglobe.com/home/g20-including-indonesia-to-take-leading-role-in-coordinatingglobal-economy-us-official/331709

thejakartaglobe.com. (2015, Februari 8). G20 Including Indonesia, to take leading role in coordinating global economy. Dipetik Februari 8, 2015, dari thejakartaglobe: thejakartaglobe.com/home/g20-including-indonesia-to-take-leading-role-in-coordinatingglobal-economy-us-official/331709

Yudhoyono, S. B. (2009). An Attempt to Cope With The Global Financial Crisis. The Indonesian Quarterly, 37/no.1, 8. 